\title{
A Review on Optimization of C. I. Engine Performance Parameters for Biodiesel Fuel Using Suitable Software
}

\author{
G. H. Kawade ${ }^{1}$, S. T. Satpute ${ }^{2}$ \\ ${ }^{I}$ P.G. Student, Department of Automobile Engineering, R. I. T. Sakharale, Maharashtra, India \\ ${ }^{2}$ Head, Department of Automobile Engineering, R. I. T. Sakharale, Maharashtra, India
}

\begin{abstract}
The increasing industrialization and motorization of the world has led to a steep rise for the demand of petroleum products. Petroleum based fuels are obtained from limited reserves also use of conventional diesel fuel causes serious problem of air pollution and effects on the environment. Hence, it is necessary to look for alternative fuels, which can be produced from renewable sources. In this work, reports about biodiesel engine performances and emissions published by highly rated journals in scientific indexes, from these reports, the effect of biodiesel on engine power, economy, and emissions of a four strokes compression ignition engine are surveyed and analyzed in detail. Also describes many researches worked in optimization of C.I. engine performance and operating parameters for biodiesel fuel using software methods. Lastly the scope and challenges being faced in this area of research are clearly described.
\end{abstract}

Keywords - Bio-diesel, Diesel Engine Performance, Exhaust Emissions, Optimization technique.

\section{Introduction:}

Bio-diesel, which can be used as an alternative diesel fuel, is made from renewable biological sources such as vegetable oil and animal fats. It is biodegradable, non-toxic and possesses low emission profiles. Also, the uses of bio-fuels are environmentally beneficial. The name bio-diesel was introduced in the United States during 1992 by the National Soy Diesel Development Board (presently National Bio-diesel Board) which has pioneered the commercialization of biodiesel in the US [1].

Use of conventional diesel fuel causes serious problem of air pollution and effects on the environment leading to effect like green house, some factors in diesel fuel results in high emission in diesel engine. The stringent emission norms have been an important driving force to develop the CI engines more environment friendly. The main pollutants from diesel engines are carbon monoxide, hydrocarbons, nitrogen oxides and Smoke intensity. The problem of increasing demand for high brake power and the fast depletion of the fuels demand severe controls on power and a high level of fuel economy. That's Many innovative technologies are developed to tackle these problems [1,2].

This recommends the intensive studies on the use of alternative fuels especially renewable ones like vegetable oils and alcohols. The use of vegetable oils as an alternative fuel for diesel engine is not a new concept. In fact early engines were demonstrated with vegetable oil. In a developing country like India where mass transportation plays an important role, the suitability of alternate fuels for a diesel fuel engine application has to be thoroughly investigated. Vegetable oils plays a prominent role in substituting diesel, since they are renewable and are easily produced in rural areas. Biodiesels such as Jatropha, Karanja, Sunflower and Rapeseed are some of the popular biodiesels currently considered as substitute for diesel. When biodiesel is used as a substitute for diesel, it is highly essential to understand the parameters that affect the combustion phenomenon which will in turn have direct impact on thermal efficiency and emission. In the present energy scenario lot of efforts is being focused on improving the thermal efficiency of IC engines with reduction in emissions. The problem of increasing demand for high brake power and the fast depletion of the fuels demand severe controls on power and a high level of fuel economy. Many innovative technologies are developed to tackle these problems $[3,5]$.

This paper gives a comprehensive review of the methods used for optimization performance and operating parameters of the C.I. engine using biodiesel fuel through suitable optimization technique or suitable software. Experimental investigation on different oils, characterization, merits, demerits and challenges faced by bio-diesel are described.

\section{Biodiesel Feedstock:}

Vegetable oils as a biodiesel feedstock it consist of edible or non-edible oil. The concept of using vegetable oil as a transportation fuel dates back to 1893 when Dr. Rudolf Diesel developed the first diesel engine to run on vegetable oil. Vegetable oil is one of the renewable fuels. Vegetable oils have become more attractive recently because of its environmental benefits and the fact that it is made. The advantages of vegetable oils as diesel fuel are their portability, ready availability, renewability, higher heat content (about 88\% of D2 
fuel), lower sulfur content, lower aromatic content, and biodegradability. The main disadvantages of vegetable oils as diesel fuel are higher viscosity, lower volatility, and the reactivity of unsaturated hydrocarbon chains [2]. Following table 2.1 shows the different type of vegetable biodiesel and their comparative properties with diesel fuel.

Table No. 2.1 Comparative Properties for different biodiesel fuel and diesel fuel $[2,5,6]$

\begin{tabular}{|l|c|c|c|c|}
\hline Fuel Properties & $\begin{array}{c}\text { Kinematic viscosity } \\
\left(\mathbf{m m}^{2} / \mathbf{s e c}\right)\end{array}$ & $\begin{array}{c}\text { Flash Point } \\
\left(\mathbf{(}^{\mathbf{0}}\right)\end{array}$ & $\begin{array}{c}\text { Density } \\
\left(\mathbf{k g} / \mathbf{m}^{\mathbf{3}}\right)\end{array}$ & $\begin{array}{c}\text { Calorific Value } \\
(\mathbf{M J} / \mathbf{k g})\end{array}$ \\
\hline Jatropha Biodiesel & 5.25 & 166 & 871 & 42.10 \\
\hline Palm Biodiesel & 4.40 & 178 & 855 & 39.70 \\
\hline Soybean Biodiesel & 4.08 & 171 & 914 & 37.9 \\
\hline Sunflower Biodiesel & 5.35 & 238 & 860 & 48.50 \\
\hline Karanja Biodiesel & 3.8 & 212 & 935 & 36.60 \\
\hline Diesel & $2-3.5$ & $60-80$ & $810-860$ & $42.5-44$ \\
\hline
\end{tabular}

\subsection{Power Performance:}

\section{Engine Performances:}

In this work, only the literatures illustrating the effect of biodiesel on engine power and/or torque are surveyed. That there are different literatures to study the effect of pure biodiesel on engine power, with biodiesel (especially with pure biodiesel), engine power will drop due to the loss of heating value of biodiesel. However, the results reported show some fluctuation. Some authors found that the power loss was lower than expected (the loss of heating value of biodiesel compared to diesel) because of power recovery. Researcher $[1,3]$ found that the respective average decrease of torque and power values of WFOME (waste frying oil methyl ester) was $4.3 \%$ and $4.5 \%$ due to higher viscosity and density and lower heating value (8.8\%). [1] Observed that the brake torque loss was $9.1 \%$ for B100 biodiesel relative to diesel at $1900 \mathrm{rpm}$ as the results of variation in heating value (13.3\%), density and viscosity [3]. Some researcher had shows that the content of biodiesel blended with diesel results in the difference in engine power performance, which has become the commonsense. Engine power will decrease with the increase of content of biodiesel.

Properties of biodiesel, especially in heating value, viscosity and lubricity, have an important effect on engine power. Heating value of fuels is an important measure of its releasing energy for producing work. So, the lower heating value of biodiesel is attributed to the decrease in engine power, which is commonly agreed by the authors who reported that engine power reduced with biodiesel [1,2]. Higher viscosity of biodiesel, which enhances fuel spray penetration, and thus improves air-fuel mixing, is used to explain the recovery in torque and power for biodiesel related to diesel in some literatures [3]. However, a few authors [4] thought that the higher viscosity results in the power losses, because the higher viscosity decreases combustion efficiency due to bad fuel injection atomization. High lubricity of biodiesel might result in the reduced friction loss and thus improve the brake effective power.

\subsection{Economy Performance:}

Most of researches agreed that the fuel consumption of an engine fueled with biodiesel becomes higher because it is needed to compensate the loss of heating value of biodiesel [1]. Reported that the difference in fuel consumption between diesel and pure biodiesel was $18.5 \%$ in mass, and it was reduced to $13.5 \%$ in volume because of higher density of biodiesel. Some authors found that the increased ratio of fuel consumption for biodiesel was more than the loss ratio of its heating value [3].

Some authors investigated that the, with increasing the content of biodiesel, engine fuel consumption will increase. For example, Godiganur et al. [4] observed this trend after they tested B10, B20, B40, B60, B80 and B100 fuels on a 3-cylinder, 4-stroke, DI diesel engine. As for the properties of biodiesel, the lower heating value, higher density and higher viscosity play primary role in engine fuel consumption for biodiesel [5]. Most of authors, who agreed that fuel consumption increased for biodiesel compared to diesel, contributed to the loss in heating value of biodiesel [4].

Some authors reported that Biodiesel engine economy is affected by engine type and its operating conditions, such as load, speed, and injection timing and injection pressure. They showed that the BSEC initially decreased with increasing of engine load until it reached a minimum value and then increased slightly with further increasing engine load for all kind of fuels (B5, B20, B50, B100 and diesel). Further, it was reported in [5] and [7] that the increase in BSFC values at full load was higher than those at partial loads for biodiesel compared to diesel.

The effect of injection timing and injection pressure on fuel consumption for biodiesel was investigated experimentally found that the fuel consumption was reduced by reducing injection advance because it is possible to optimize combustion, and by improving performances especially at low and medium speed with 
respect to nominal injection advance operation [7]. The use of a turbocharged engine or a low heat release engine, will improve biodiesel engine economy. Engine operating conditions, such as load, speed, injection timing and injection pressure, etc., are also influential to biodiesel engine economy [7].

\subsection{Efficiency Performance:}

Most of researches reported that the different efficiency of biodiesel from the experiments it was observed that BTE increases with the load for both diesels as well as pongamia oil methyl ester blends [7]. Mechanical Efficiency of sunflower biodiesel blends has been compared with diesel fuel at various loads. He had observed that the Mechanical Efficiency for B20 blend was higher than the diesel and other blends operation over entire load range [8]. Also Researcher [10] had shows that the volumetric efficiency for diesel is higher than the other blend operations over entire load range. This is due to higher exhaust gas temperature released after the combustion process.

\subsection{PM Emissions of Biodiesel:}

\section{Emissions:}

Some authors shows that the use of biodiesel instead of diesel fuel causes the reduce in PM emissions. Some authors found that there was no difference in PM emissions for biodiesel relative to diesel fuel. biodiesel from sunflower and olive oil on a single cylinder stationary diesel engine found the maximum PM emissions for the $10 \%$ blends and the minimum PM emissions for the 50\% blends at the different loads [8]. The trend which PM emissions of biodiesel will be reduced is due to lower aromatic and sulfur compounds and higher cetane number for biodiesel [5], but the more important factor is the higher oxygen content. Majority of researchers had reported that, the larger engine load is the greater PM emissions of biodiesel [1].

\subsection{Smoke Emission of Biodiesel:}

Smoke formation occurs at the extreme air deficiency. Air or oxygen deficiency is locally present inside the diesel engines. It increases as the air to fuel ratio decreases. Researcher had reported that the smoke emissions are increased with increase in the load for all compression ratios, as the formation of smoke is strongly dependent on the load [7]. For biodiesel operation the smoke values reduced because of the atomic bounded oxygen which helps in better combustion, thus reducing the smoke. Some researcher had reported that the decrease in smoke for JB20, JB50, JB100, PB20, PB50 and PB100 are 28.57\%, 40.9\%, 64.28\%, 29.22\%, $44.15 \%$ and $69.48 \%$ was observed at the rated speed, respectively [12].

\subsection{NOx Emissions of Biodiesel:}

Most of the author's literatures believe that the use of pure biodiesel causes the increase in NOx emissions. Formation of NOx is dependent on the operating temperature of the cylinder and the oxygen availability. Advance in injection and thus advance in combustion for biodiesel affect NOx emissions, [3] higher the cetane number of biodiesel shortens ignition delay and thus combustion advances. Researcher reported a maximum of $15 \%$ increase in NOx emissions for B100 was observed at high load condition as the results of $12 \%$ oxygen content of the B100 and higher gas temperature in combustion chamber $[4,3]$.

According to mechanism of NOx formation, engine load plays very important role in NOx formation. NOx formation increases as load is increased which is as the results of higher combustion temperature due to higher engine load. The vast majority of literatures reported that NOx emissions will increase when using biodiesel. This increase is mainly due to higher oxygen content for biodiesel. The use of EGR will reduce NOx emissions of biodiesel, but due to the change of combustion characteristics for biodiesel, [12].

\subsection{CO Emissions of Biodiesel:}

Researcher had reported that the $\mathrm{CO}$ emissions reduce when diesel is replaced by pure biodiesel. A higher reduction in $\mathrm{CO}$ emissions was shown by $[1,3]$, who observed that the reducing range of $\mathrm{CO}$ emission was $73-94 \%$ for the karanja methyl ester (B100) and its blends (B20, B40, B60 and B80) compared to diesel. $\mathrm{CO}$ emissions of blends reduce due to increasing in oxygen content. It was showed that the commonly that $\mathrm{CO}$ emissions reduce when using biodiesel due to higher oxygen content and lower carbon to hydrogen ratio in biodiesel compared to diesel [14].

\subsection{HC Emissions of Biodiesel}

Most of researches showed that $\mathrm{HC}$ emissions for biodiesel reduce with the increase of biodiesel content. Some others researchers [1,3] reported the considerably similar decrease in HC when using biodiesel. For example, [1] reported that the 5 different biodiesels reduced $\mathrm{HC}$ emission by $45-67 \%$ on average compared with diesel fuel. Some author explained that the lower heating value of the pure biodiesel implies higher fuel consumptions and therefore it could produce high local fuel to- air ratios which caused an increase in HC 
emissions. $\mathrm{HC}$ emissions were lower for biodiesel blends. HC emissions in the exhaust had decreased with the increasing amount of biodiesel in the fuel blend. The inbuilt oxygen content in its molecular structure may be responsible for complete combustion and thus reducing the HC levels [12].

\section{Optimization Technique:}

Some of the researcher had work on the optimization of diesel engine performance and operating parameters using different technique as suitable software [7], as like taguchi method, Matlab, artificial neural network. These techniques are computationally efficient for optimization requiring hundreds of function evaluations, this tool that saves cost and time in developing new models and methodologies for overall engine management [8]. Some research work has shown that, for analyzing complex problems of emission analysis of biodiesels and their blends, artificial neural network is suitable, adaptable and flexible computing tool that can be used for diagnostic purposes. There by, time consuming, tedious and costly experiments can be avoided.

Garg et al. [9] this paper presents overview of applications of artificial neural networks (ANN) in the field of engine development. They had work on the management engine operating parameters. They described two back-propagation learning algorithms are used to predict of the torque, power, specific fuel consumption, and smoke emission of diesel engine using different injection pressure and engine speed. Balajiganesh et al. [10] had work on the Optimization of Compression Ignition Engines through advanced artificial neural network using Matlab. The engine is operated by using diesel and sunflower oil blends and calculate optimized performance as like indicated power, brake power, break mean effective pressure, indicated mean effective pressure and specific fuel consumption. Also some researcher for ex. Mudgal et al. [11] Work on the Prediction of Emissions from Biodiesel Fueled Transit Buses Using Artificial Neural Networks. Shivakumar et al. [12] Researcher had work on the Experimental investigation on the Performance parameters and Exhaust emissions from the four stroke C.I. engine operated on honge methyl ester. Back-propagation algorithm was used to train the network. In this work they selected the inputs for the ANN are blend percentage (B), load percentage (W), and the compression ratio (CR). The output parameters from the ANN are Brake thermal efficiency (BTE), Brake specific energy consumption, (BSEC), Exhaust gas Temperature and the emissions which include Oxides of nitrogen (NOx), Smoke (SN), Unburnt Hydrocarbon (UBHC), and Carbon Monoxide (CO). Lastly he had investigated the ANN results showed good correlation between the ANN predicted values and the desired values for various engine performance values and the exhaust emissions.

Some researcher had worked on the taguchi approach for the optimization of performance and operating parameters of the diesel engine. For example, Sivaramakrishnan and Ravikumar [14] worked on the optimization of the direct injection (DI) single cylinder diesel engine with respect to brake power, fuel economy and emissions through experimental investigations and DOE methods. Researcher [15] had work on the experimental investigations conducted on a single cylinder DI diesel engine using Eucalyptus oil mixed with diesel fuel. Taguchi method of optimization predicted optimum level of parameters within 9 trials and the $40 \mathrm{Eu}$ blend found working satisfactorily at optimum setting, also in this work he had investigated the NOx emission found while working with 40Eu blend at optimum level. Here for optimization purpose he had use the orthogonal array with four columns and nine rows were used to design Taguchi experiment. Also lastly he had investigate the 50\% smoke reduction was achieved with 40Eu operation [15]. The purpose of analysis of variance (ANOVA) is to investigate the percentage contribution of variance over the response parameter [15]. Lastly he had investigated the Taguchi method of optimization predicted optimum level of parameters within working satisfactorily at optimum setting.

Some researchers states that the taguchi is most effective method for optimization of diesel engine performance parameters. For example, $[15,16]$ in this work consist an experimental study that involves an application of the Taguchi method and grey relational analysis to determine the optimum factor level to obtain optimum multiple performance characteristics of a diesel engine run with different low-percentage thumba biodiesel-diesel blends [17]. Taguchi method of optimization predicted optimum level of parameters within 9 trials and the 40 Turpentine blend found working satisfactorily at optimum setting. Lastly he proved that the blending of turpentine with diesel fuel up to $40 \%$ increases the engine Performance without much more effect on emission.

\section{Challenges:}

The major challenges that face the use of Biodiesel as a fuel in internal combustion engine are listed as below.

i. The price of vegetable oil is dependent on the feed stock price;

ii. Feed stock homogeneity, consistency and reliability are questionable;

iii. Homogeneity of the product depends on the supplier, feed stocks and production methods;

iv. Storage and handling is difficult (particularly stability in long term storage);

v. Flash point in blends is unreliable;

vi. Compatibility with I.C. engine material needs to be studied. 
vii. Cold weather operation of the engine is not easy with vegetable oils;

viii. Continuous availability of the vegetable oils needs to be assured before embarking on the major use of it in I.C. engines.

\section{Technical Difficulties:}

The major technical areas with respect to the use of biodiesel as fuels in I.C. engines, which need to be further following attention are the most important:

i. Development of less expensive quality tests;

ii. Study of the effects of oxidized fuel on engine performance and its durability

iii. Emission testing with a wide range of feed stocks

iv. Efforts to be focused on responding to fuel system performance, material compatibility, petroleum additive compatibility and low fuel stability under long term storage;

v. Continued engine performance, emissions and durability testing in a variety of bio-diesel fuels for engine and need to be develop to increase consumer and manufacturer confidence.

vi. Environmental benefits offered by vegetable oil over diesel fuel needs to be Popularized.

vii. Studies are needed to reduce the production cost, develop low cost feed stocks and identify potential markets in order to balance cost and availability

\section{Conclusion:}

Biodiesel produced from vegetable oil (edible and non edible oil) renewable sources, it is a more sustainable source of energy and it will be play an increasingly significant role in providing the energy requirements for transportation. The Properties of biodiesel closely related to diesel fuel. The use of biodiesel will lead to loss in engine power mainly due to the reduction in heating value of biodiesel compared to diesel fuel. Increase in biodiesel fuel consumption, due to low heating value and high density and viscosity of biodiesel, has been found. PM emissions $\mathrm{HC}, \mathrm{CO}$ emissions for biodiesel are significantly reduced, compared with diesel fuel. But NOx emissions may increases when using the biodiesel, this increase is mainly due to higher oxygen content for biodiesel.

From the literature survey it can be concluded that the blends of biodiesel with small Content by volume could replace diesel in order to help in controlling air pollution and improving engine performance of power and economy of engine when using biodiesel blending with diesel fuel.

From the literature it may concluded that the Optimization of C.I. engine performance and operating parameters through different software is most suitable technique. Also it is more accurate technique and less time consuming as compaired to experimental method. Use of Artificial Neural networks for optimizing the C.I Engine parameters is most suitable technique. Therefore ANN will be a very good tool to optimize engines parameters in the future. Also the taguchi method can be effectively used for the investigation of multiple performance characteristics of a diesel engine.

\section{References:}

[1] Jinlin Xue, Tony E. Grift, Alan C. Hansena, 'Effect of biodiesel on engine performances and emissions', Renewable and Sustainable Energy (2011)

[2] Mustafa Balat, Havva Balat, 'Progress in biodiesel processing', Applied Energy, Vol. 87, 1815-1835, (2010).

[3] Magin Lapuerta, Octavio Armas, Jose Rodriguez-Fernandez, 'Effect of biodiesel fuels on diesel engine emissions', Progress in Energy and Combustion Science, vol. 34, 198-223, (2008).

[4] T.T. AL-Shemmeri, S. Oberweis, 'Correlation of the NOx emission and exhaust gas temperature for biodiesel', Applied Thermal Engineering, vol. 31, 1682-1688 (2011).

[5] K. Sivaramakrishnan, P. Ravikumar, 'Determination of Cetane Number of Biodiesel and It's Influence on Physical Properties', ARPN Journal of Engineering and Applied Sciences Vol. 7, No. 2, (2012).

[6] Aldo Okullo, A. K. Temu, P. Ogwok, J. W. Ntalikwa, 'Physico-Chemical Properties of Biodiesel from Jatropha and Castor Oils' International Journal of Renewable Energy Research Vol.2, No.1, (2012).

[7] M. Venkatraman, G. Devaradjane, 'Computer Modeling of a CI Engine for Optimization of Operating Parameters Such as Compression Ratio, Injection Timing and Injection Pressure for Better Performance and Emission Using Diesel-Diesel Biodiesel Blends', American Journal of Applied Sciences vol. 8, 897-902, (2011).

[8] R.Manjunatha, P. Badari Narayana, K. Hema Chandra Reddy, 'Application of Artificial Neural Networks for Emission Modelling of Biodiesels for a C.I Engine under Varying Operating Conditions', modern applied science vol.4 (2010).

[9] Anant Bhaskar Garg, Parag Diwan, Mukesh Saxena, 'Artificial Neural Networks based Methodologies for Optimization of Engine Operations' International Journal of Scientific \& Engineering Research, (2012).

[10] N. Balajiganesh, B.Chandra Mohan Reddy, 'Optimization of C.I Engine Parameters Using Artificial Neural', International Journal of Mechanical and Industrial Engineering (IJMIE), ISSN No. 2231 -6477, Volume-1, Issue-2, (2011).

[11] Abhisek Mudgal, Kasthurirangan Gopalakrishnan, Shauna Hallmark, 'Prediction of Emissions from Biodiesel Fueled Transit Buses Using Artificial Neural Networks', International Journal for Traffic and Transport Engineering, (2011).

[12] Shivakumar, Srinivas Pai P., Shrinivasa Rao B. R, Samaga B. S., 'Performance and Emission Characteristics of a 4 Stroke C.I. Engine operated on Honge Methyl Ester Using Artificial Neural Network', ARPN Journal of Engineering and Applied Sciences (2010).

[13] Yusuf Cay, Adem cicek, Fuat Kara, Selami Sagiroglu, 'Prediction of Engine Performance for an Alternative Fuel Using Artificial Neural Network', Applied Thermal Engineering, Elsevier (2012). 
[14] K. Sivaramakrishnan, P. Ravikumar, 'Performance Optimization Karanja Biodiesel Engine Using Taguchi Approach and Multiple Regressions', ARPN Journal of Engineering and Applied Sciences,(2012).

[15] A. Karnwal, M. M. Hasan, N. Kumar, A. N. Siddiquee, Z. A. Khan, 'Multi-Response Optimization of Diesel Engine Performance Parameters Using Thumba Biodiesel-Diesel Blends by Applying the Taguchi Method and Grey Relational Analysis, International Journal of Automotive Technology, Vol. 12, No. 4, 599-610, (2011).

[16] Tamilvendhan D, Ilangovan V., Karthikeyan R., 'Optimization of Engine Operating Parameters For Eucalyptus Oil Mixed Diesel Fueled DI Diesel Engine Using Taguchi Method', ARPN Journal of Engineering and Applied Sciences, Vol.6, ( 2011).

[17] Karthikeyan R., Nallusamy N., Alagumoorthi N., 'Optimization of Engine Operating Parameters for Turpentine Mixed Diesel Fueled Di Diesel Engine Using Taguchi Method', Modern Applied Science, Vol. 4, (2010). 